\title{
Evaluation of timed barium esophagram after per-oral endoscopic myotomy to predict clinical response
}

\section{다 (i) $(3)$}

\section{Authors}

John M. DeWitt ${ }^{1}$, Robert M. Siwiec ${ }^{1}$, Anthony Perkins², Daniel Baik¹, William R. Kessler ${ }^{1}$, Thomas V. Nowak ${ }^{1}$, John M.

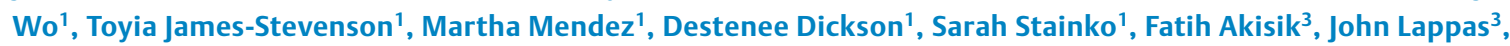
Mohammad A. Al-Haddad ${ }^{1}$

\section{Institutions}

1 Department of Gastroenterology and Hepatology, Indiana University Health Medical Center, Indianapolis, Indiana, United States

2 Department of Biostatistics, Indiana University Health Medical Center, Indianapolis, Indiana, United States

3 Department of Radiology, Indiana University Health Medical Center, Indianapolis, Indiana, United States

submitted 17.3.2021

accepted after revision 22.6.2021

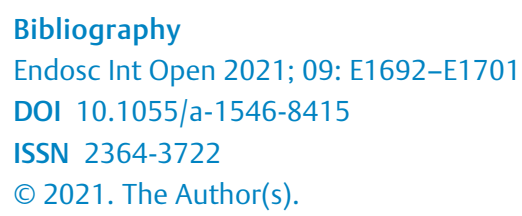

This is an open access article published by Thieme under the terms of the Creative Commons Attribution-NonDerivative-NonCommercial License, permitting copying and reproduction so long as the original work is given appropriate credit. Contents may not be used for commercial purposes, or adapted, remixed, transformed or built upon. (https://creativecommons.org/licenses/by-nc-nd/4.0/)

Georg Thieme Verlag KG, Rüdigerstraße 14,

70469 Stuttgart, Germany

Corresponding author

John DeWitt MD, FACG, FACP, FASGE, AGAF, Professor of Medicine, Division of Gastroenterology and Hepatology, Indiana University Health Medical Center, 550 N. University Blvd., UH 4100, Indianapolis, IN 46202, United States Fax: +1-317-948-8144

jodewitt@iupui.edu

Supplementary material is available under https://doi.org/10.1055/a-1546-8415

\section{ABSTRACT}

Background and study aims The aim of this study was to evaluate whether timed barium esophagram within 24 hours post-per-oral endoscopic myotomy (POEM) (TBE-PP) could predict clinical outcomes.

Patients and methods This was a single-center retrospective study of prospectively collected data on consecutive patients with $\geq 6$-month follow-up who underwent POEM followed by TBE-PP. Esophageal contrast retention 2 minutes after TBE-PP was assessed as Grade $1(<10 \%), 2$ (10\%$49 \%), 3(50 \%-89 \%)$ or 4 (>90\%). Eckardt score, esophagogastroduodenoscopy (EGD), high-resolution manometry (HRM) and function lumen imaging probe (FLIP) of the esophagogastric junction (EGJ) were obtained at baseline. These tests along with $\mathrm{pH}$ testing of antisecretory therapy were repeated 6 and 24 months after POEM. Clinical response by Eckardt score $\leq 3$, EG)-distensibility index (EG)DI) $>2.8 \mathrm{~mm}^{2} / \mathrm{mm} \mathrm{Hg}$, and integrated relaxation pressure $($ IRP) $<15 \mathrm{~mm} \mathrm{Hg}$ and incidence of gastroesophageal reflux disease (GERD) were compared by transit time.

Results Of 181 patients ( $58 \%$ male, mean $53 \pm 17 \mathrm{yr}$ ), TBEPP was classified as Grade 1 in 122 (67.4\%), Grade 2 in 41 (22.7\%), Grade 3 in 14 (7.7\%) and Grade 4 in 4 (2.2\%). At 6 months, overall clinical response by ES (91.7\%), IRP (86.6\%), EGJ-DI (95.7\%) and the diagnosis of GERD (68.6\%) was similar between Grade 1 and Grade 2-4 TBE-PP. At 24 months, Grade 1 had a higher frequency of a normal IRP compared to Grades $2-4(95.7 \%$ vs. $60 \%, P=0.021)$ but overall response by ES (91.2\%), EGJ-DI (92.3\%) and the diagnosis of GERD (74.3\%) were similar.

Conclusions Contrast emptying rate by esophagram after POEM has limited utility to predict clinical response or risk of post-procedure GERD.

\section{Introduction}

Idiopathic achalasia is a primary esophageal motor disorder characterized by aperistalsis and incomplete relaxation of the lower esophageal sphincter [1]. Treatment focuses on disrup- tion of the lower esophageal sphincter by pneumatic dilation, Heller myotomy, or most recently, peroral endoscopic myotomy (POEM). Recent randomized trials demonstrate that symptom relief with POEM is superior to pneumatic dilation [2] and noninferior to Heller myotomy [3]. Therefore, where available, 
POEM has become the preferred primary management for patients with idiopathic achalasia.

Because POEM involves multiple steps including mucosal incision, submucosal dissection, myotomy and incision closure, fluoroscopic esophagram with oral contrast [4-7] or computed tomography (CT) scan (with [8] or without [9] oral contrast) is frequently performed to evaluate for procedure-related adverse events (AEs). Previous studies report that esophagram [5-7] and CT scans [8-9] after POEM often describe findings such as pneumoperitoneum or pneumomediastinum which are not usually clinically relevant or require repeat intervention. Furthermore, these tests are associated with increased cost, radiation exposure and may lead to unnecessary procedures for incidental findings $[6,7]$. However, imaging may demonstrate contrast leaks within the wall (termed intramural dissection or contained leaks) or extravasation and it remains unclear whether intervention is required for contained leaks.

Timed barium esophagram (TBE) is often used to evaluate the efficacy of interventions in patients with achalasia, particularly after pneumatic dilation [10-12] or surgical myotomy. TBE after dilation can identify patients who may require repeat intervention [11] and is more effective than patient reported outcomes to predict treatment response [12]. Despite these findings, delay in esophagram contrast passage after POEM does not appear to predict clinical outcomes $[4,13,14]$ thus raising questions about its utility in this setting.

Given its apparent limited utility in predicting clinically relevant AEs or patient outcomes, some authors have suggested that post-POEM imaging may not be warranted [5, 6, 9]. However, studies evaluating the role of esophagram after POEM are often retrospective $[4-7,9,13,14]$ or use non-standardized or unspecified esophagram protocols $[5,7,13]$ to report clinical outcomes. Therefore, precise determination of the utility of imaging after POEM to determine clinical response or need for post-procedure intervention remains inconclusive.

In this retrospective, single-center study, we sought to determine the utility of 2-minute timed post-POEM barium esophagram (TBE-PP) transit speed to predict relevant short-term (6-month) and long-term (24-month) clinical outcomes. Our secondary aim was to evaluate the safety of conservative management in patients with intramural dissection after POEM in whom no other worrisome clinical signs were present. We hypothesized that delayed TBE-PP would not predict assessed clinical outcomes and reintervention was not required for contained submucosal leaks in stable patients.

\section{Patients and methods}

\section{Patient selection and study design}

This IRB-approved study (ClinicalTrials.gov ID NCT02770859) enrolled consecutive patients who underwent POEM for achalasia or esophagogastric outlet obstruction (EGJOO) at Indiana University Health Hospital in Indianapolis between 2016 and December 2019. All data were collected prospectively and analyzed retrospectively. TBE-PP within 24 hours of POEM was performed in all patients as standard of care. Patients with followup Eckardt scores or any objective testing (esophageal pH mon- itoring, EGD, hig- resolution esophageal manometry [HRM] or functional luminal impedance planimetry [FLIP]) performed $\geq 6$ months after POEM comprised the study population. Patients were excluded for any of the following reasons: 1) baseline Eckardt score $<3$ or IRP $<15 \mathrm{~mm} \mathrm{Hg}$; 2) follow-up <6 months; or 3) follow-up $\geq 6$ months but no objective testing or Eckardt score completed. Written informed consent was obtained from all patients to participate in the study. All authors had access to the study data and reviewed and approved the final manuscript.

\section{Pre-procedure evaluation}

Prior to POEM, key demographic information including gender, body mass index (BMI), age, and prior therapy (botulinum toxin injection, pneumatic dilation or surgical myotomy) for the esophageal motility disorder was recorded. Baseline patient reported frequency of dysphagia, chest pain, regurgitation, and weight change were recorded and an Eckardt score (range: 012 , with higher score indicating more severe disease) was calculated [15]. Baseline EGD, HRM and beginning in 2017, FLIP of the esophagogastric junction (EGJ) was performed.

\section{High-resolution esophageal manometry}

High-resolution esophageal manometry (HRM) studies were performed in the left lateral position with 30-degree head-elevation. A 4.2-mm, solid-state, manometry-impedance catheter with 36 circumferential pressure sensors at 1 -cm intervals and 18 impedance channels (Medtronic, Minneapolis, Minnesota, United States) was placed transnasally and positioned with the pressure sensors spanning a length extending from the hypopharynx through the esophagus and 3 to $5 \mathrm{~cm}$ into the stomach. Once the catheter was in position and following an acclimation period, baseline resting EGJ morphology and pressure was assessed during normal respiration without swallows. Ten 5-mL liquid swallows were performed in the supine position. Study swallows were analyzed using the ManoView version 3.0 analysis software (Medtronic Minneapolis, Minnesota, United States) and Chicago Classification version 3.0 [16].

\section{EGD and FLIP procedures}

EGD and FLIP were performed in the left lateral position under propofol sedation. The 16-cm FLIP (EndoFLIP EF-100, EF-322N or EF-325N, Medtronic, Inc, Shoreview, Minnesota, United States) was initially calibrated to atmospheric pressure and subsequently (with the endoscope withdrawn) passed transorally across the EGJ to ensure that at least 2 sensors were in the stomach. Endoscope visualization and rarely forceps assistance was required to facilitate catheter passage into the stomach. Endoscope insertion was done to confirm the balloon had traversed the EG] and was positioned at the midpoint of the impedance sensors prior to inflation. Following endoscope removal, controlled, stepwise volumetric distensions of 20,30, and $40 \mathrm{~mL}$ and beginning in July 2017, $50 \mathrm{~mL}$ were performed, maintaining each for at least 30 seconds while measurements were obtained. With each distention, the EGJ cross-sectional area, intrabag pressure, and EGJ diameter were assessed. If bag migration was suspected or peristalsis occurred, the bag was repositioned and the measurement repeated. The EGJ dis- 
tensibility index (EGJ-DI) at each distension volume was calculated by dividing the EG] cross sectional area by the intra-bag pressure and reported as $\mathrm{mm}^{2} / \mathrm{Hg}[17]$.

\section{POEM procedure}

All POEM procedures were performed by two gastroenterologists with patients in the supine position under general anesthesia. EGD was first performed to clear the esophagus and stomach of any debris. A total of $120 \mathrm{~mL}$ of dilute gentamicin solution $(160 \mathrm{mg} / 100 \mathrm{~mL}$ of normal saline) was then instilled in the lower half of the esophagus and completely suctioned. A transparent cap was inserted on the distal end of the endoscope. Approximately 8 to $10 \mathrm{~cm}$ proximal to the EGJ, a mixture of saline with methylene blue was injected into the submucosa. After adequate lift, a longitudinal 2 to $3 \mathrm{~cm}$ mucosal incision (ENDO CUT Q, Effect 3, Cut Duration 2, Cut Interval 1) was made with a Hybrid T knife (Erbe USA, Inc., Marietta, Georgia, United States) using an electrosurgical generator (Erbe VIO 300 D, Erbe USA, Inc., Marietta, Georgia, United States) to allow entrance to the submucosal space. A submucosal tunnel was created and through careful dissection extended (using Forced Coag, Effect 2, maximum 50 watts or ENDO CUT Q as above) for 2 to $3 \mathrm{~cm}$ into the gastric cardia. Bleeding or potentially bleeding sites were treated with Coagulation hemostatic forceps (Olympus America, Center Valley, Pennsylvania, United States) using soft coagulation (Effect 5, 80 Watts) current. A myotomy was performed using both ENDO CUT Q as above or Spray Coagulation (Effect 2, 35 Watts) in a proximal-to-distal direction and extended approximately $2 \mathrm{~cm}$ into the gastric cardia. After myotomy, the entry of the tunnel was then closed with endoscopic clips (Resolution, Boston-Scientific, Inc., Marlborough, Massachusetts, United States) and/or endoscopic suturing (Overstitch, Apollo Endosurgery, Austin Texas, United States). The orientation of the submucosal tunnel (i. e., anterior vs. posterior), myotomy type (circular alone vs. full thickness), and total myotomy length were recorded.

\section{Esophagram protocol}

TBE-PP was performed by a registered radiologist assistant within 24 hours of POEM. The exam started with upright ingestion of $100 \mathrm{~mL}$ of water-soluble contrast (Gastrografin, EZ-EM Canada, Inc., Anjou Quebec). If an extramural leak was excluded, $100 \mathrm{~mL}$ of barium suspension (EZ-EM Canada, Inc., Anjou Quebec) was given immediately thereafter to complete the exam and confirm absence of extravasation. The quantity of contrast remaining in the esophagus 2 minutes after ingestion of barium was estimated prospectively by a gastrointestinal radiologist as: Grade $1(<10 \%)$, Grade 2 (10\%-49\%), Grade 3 (50\%-89\%) or Grade 4 (>90\%) transport. If no contrast remained after one minute, then no further images were obtained. An esophageal lumen diameter midway between the upper and lower sphincter was measured and topography assessed for sigmoid configuration. A sigmoid esophagus was considered dilation to $\geq 10 \mathrm{~cm}$ in diameter and/or a tortuous lumen towards the EG] [18]. The presence of any intramural dissection (contained leak) or extramural leakage (non-contained leak) of contrast was also noted. Repeat endoscopic intervention was considered for extramural leak but only for a contained leak if symptoms of severe chest pain, fever or odynophagia were present. If no extramural leak was identified with both contrast agents, then a clear or full liquid diet was started within four hours. Incidental findings such as subcutaneous emphysema, gastric pneumatosis, pneumoperitoneum or a pleural effusion were only tracked if additional interventions were required to manage suspected complications based on these results. After POEM, patients were instructed to take a proton-pump inhibitor twice daily for only 2 weeks and asked to restart only for recurrent symptoms or heartburn.

\section{Follow-up after POEM}

Six and 24 months after POEM, patients returned to our hospital for one or more of the following: Eckardt score calculation, esophageal pH testing, HRM, EGD, and FLIP of the EGJ. Evaluations and diagnostics were performed after patients discontinued all anti-secretory therapy for at least one week. Patients were also queried about the presence of any heartburn and frequency of any use of proton pump inhibitors (PPIs). If patients were unable or unwilling to return for objective testing then information about Eckardt scores, PPI use, and heartburn were made by telephone call by a research nurse blinded to TBE-PP results. The severity of any endoscopic evidence of esophagitis was classified by the Los Angeles Classification [19].

\section{Esophageal pH testing}

Measurement of esophageal acid exposure (Bravo, Medtronic, Minneapolis, Minnesota, United States) for 48 hours was obtained 6 months and 24 months after POEM by wireless ambulatory $\mathrm{pH}$ monitoring [20]. Prior to placement, the Bravo $\mathrm{pH}$ capsule was calibrated according to the manufacturer's protocol. The Bravo delivery system was passed orally, positioned 6 $\mathrm{cm}$ proximal to the EG] and deployed in standard fashion. The diagnosis of conclusive, inconclusive, or absent GERD was determined using the Lyon consensus criteria [21]. Inconclusive or absent GERD for the current study was considered absence of GERD.

\section{Definitions of clinical response}

Clinical response after POEM was defined by three independent metrics: Eckardt Score $\leq 3$ [22] in absence of repeat intervention for treatment failure, EGJ-DI $>2.8 \mathrm{~mm}^{2} / \mathrm{mm} \mathrm{Hg}$ at any balloon distention [23], and IRP $<15 \mathrm{~mm} \mathrm{Hg}$ [16].

\section{Statistical analysis}

Patients were compared by speed of transport on TBE-PP: a) Grade 1 vs. Grades 2-4; and b) Grades 1 and 2 vs. Grades 3 and 4 . Continuous variables are described as means \pm standard deviations or medians with ranges. Dichotomous variables are described as proportions. Two sample t-tests for continuous outcomes and Fisher's exact test for categorical variables to test for differences in patient reported outcomes and objective testing between the two groups. A logistic regression was used to determine if dichotomous clinical response outcomes differed by TBE-PP grade adjusting for esophageal motility disorder, esophageal width, presence of a sigmoid esophagus and 
any pre-procedure therapy. Analysis of covariance (ANCOVA) models were used to compare continuous outcome measures by TBE-PP grade adjusting for type of esophageal motility disorder, esophageal width, presence of a sigmoid esophagus and any pre-procedure therapy. $P<0.05$ was used to determine significance. All analyses were performed using SAS v9.4 (Cary North Carolina, United States).

\section{Results}

\section{Study population}

During the study period, 228 patients underwent POEM for achalasia or EGJOO and 47 (21\%) were excluded due to refusal to return phone calls or for follow up exams $(n=32)$, failure to sign consent $(n=6)$ or severe comorbidities preventing testing $(n=9)$. The baseline characteristics of the 181 consecutive patients ( $58 \%$ male, mean $53 \pm 17$ yrs.) who underwent POEM are shown in $>$ Table 1. Mean Eckardt score was $7.9 \pm 1.8$ and the most common esophageal motor disorder was type 2 achalasia (62.4\%). Previous therapy was performed in $52.5 \%$ of patients. Overall, 24 (13.4\%) had a sigmoid configuration. TBE-PP was classified as Grade 1 in 122 (67.4\%), Grade 2 in 41 (22.7\%), Grade 3 in 14 (7.7\%) and Grade 4 in 4 (2.2\%). Mean esophageal width was larger in the Grade 2 to 4 group $(4.0 \pm 1.8 \mathrm{~cm})$ compared to Group $1(3.1 \pm 1.0 \mathrm{~cm} ; P<0.001)$; otherwise, the two groups were similar.

Intramural dissection was found in seven patients (3.8\%) either at the site of the tunnel mucosotomy clip closure $(n=4)$ or GE junction $(n=3)$. In one patient with intramural dissection, POEM was also complicated intraoperatively by pneumothorax requiring chest tube insertion. Based on the subsequent finding of a contained leak on esophagram, a fully covered stent was inserted the day following POEM. In the other six patients with intramural dissection, no further intervention was performed for the contained leak and a clear or full liquid diet was started within 24 hours of POEM. In the remaining 174 patients, no findings on esophagram prompted change in clinical care.

\section{Six-month follow-up}

At 6 months after POEM, follow-up was available for Eckardt scores $(n=181)$, HRM $(n=127)$, FLIP $(n=140)$, EGD $(n=146)$ and $\mathrm{pH}$ testing $(\mathrm{n}=121)$. Overall clinical response by Eckardt score (91.7\%), IRP (86.6\%) and EGJ-DI (95.7\%) was similar between patients with Grade 1 transport and those with Grades 2 to 4 transport ( $>$ Table 2 ). Furthermore, there was no difference in post-POEM mean IRP, mean EGJ-DI $>2.8 \mathrm{~mm}^{2} / \mathrm{mm} \mathrm{Hg}$, or mean EGJ-DI and at any $(20-50 \mathrm{~mL})$ balloon distention. Overall, GERD was diagnosed in $68.6 \%$ of the 127 patients who had EGD, pH testing, or both but the frequency was similar between the two groups. Esophagitis was present in $69.9 \%$ of the 146 patients who had follow up EGD, including $11.0 \%$ with LA Grade C and $4.1 \%$ with LA Grade D esophagitis. Heartburn was reported in $31.6 \%$ of patients and $31.2 \%$ were taking PPIs either daily or weekly. The overall rate of esophagitis, patient reported heartburn and PPI use were similar between the two groups.

\section{Twenty-four month follow-up}

At 24 months after POEM, follow-up was available for at least one variable in $73(40 \%)$ patients. TBE-PP was Grade 1 in 50 (68.4\%), Grade 2 in 15 (20.5\%), Grade 3 in 6 (8.2\%), and Grade 4 in $2(2.9 \%)$. Follow-up was available for Eckardt scores $(n=$ 68), HRM ( $n=33)$, FLIP ( $n=39)$, EGD $(n=39)$, and $p H$ testing ( =33). Overall clinical response by Eckardt score, IRP and EGJ-DI was $91.2 \%, 84.9 \%$ and $92.3 \%$, respectively ( Table 3 ). Group 1 had a higher frequency of a normal IRP compared to Groups 2 to $4(95.7 \%$ vs. $60 \%, P=0.021)$ but response by Eckardt score and EGJ-DI were similar between the two groups. There was no difference in post-POEM mean IRP, EGJ-DI $>2.8 \mathrm{~mm}^{2} / \mathrm{mm} \mathrm{Hg}$ or mean EGJ-DI and at any $(20-50 \mathrm{~mL})$ balloon distention. GERD was diagnosed in $74.3 \%$ of the 35 patients who had EGD, $\mathrm{pH}$ testing or both but the frequency was similar between the two groups. Esophagitis was present in $77.9 \%$ of 39 patients who had follow up EGD, including $7.7 \%$ with LA Grade C or and $5.1 \%$ with LA Grade D esophagitis. Heartburn was reported in $42.6 \%$ of patients and $25.5 \%$ reported taking a PPI at least daily or weekly. The overall rate of esophagitis, patient reported heartburn, and PPI use was likewise similar between the two groups.

Multivariate analysis results comparing grade 1 with grades 2 to 4 are presented in Supplemental Table 4. After adjusting for baseline IRP and other clinical characteristics, patients with TBE-PP grades 2 to 4 have higher IRP scores at 24 months than patients with grade 1 . Increasing baseline IRP was also significantly associated with increasing IRP at 24 months. No other clinical outcomes differed significantly between grade 1 and grade 2 to 4 patients after adjusting for clinical characteristics.

\section{Comparison between Groups 1 and 2 versus Groups 3 and 4}

Mean esophageal width was larger in the Grades 3 to $4(4.6 \pm$ $2.0 \mathrm{~cm})$ compared to Group 1 group $(3.3 \pm 1.2 \mathrm{~cm} ; P<0.001)$; otherwise, the two groups were similar (Supplemental Table 1). At 6 months after POEM (Supplemental Table 2), clinical response by EGJ-DI was higher in the Grade 1 to 2 group compared to the Grade 3 to 4 group (97.6\% vs. $81.2 \%, P=0.02$ ). At 24 months after POEM (Supplemental Table 3), clinical response by IRP was higher in the Grade 1 to 2 group compared to the Grade 3 to 4 group ( $95.7 \%$ vs. $81.2 \%, P=0.02$ ). Otherwise, clinical response by Eckardt score, EGJ-DI or IRP or the incidence of GERD, heartburn, esophagitis and PPI use were similar between the two groups.

Multivariate analysis results comparing grade 1,2 with grades 3,4 are presented in Supplemental Table 5. After adjusting for clinical characteristics, DI at 20,30,40 and 50 at 6 months are no longer significantly different between the grade categories. Only one comparison between grades 1 and 2 versus grades 3 and 4 remained significant after adjustment. Any DI $>2.8$ at 6 months was significantly lower for grade 3 to 4 patients than grade 1 to 2 patients. 
- Table 1 Demographics, baseline features and results of POEM procedure in 181 consecutive patients with achalasia or EGJOO and at least 6-month follow-up with Grade 1 ( $<10 \%$ contrast retention) or Grade 2-4 (> $10 \%$ contrast retention) post-POEM timed barium esophagram (TBE-PP) transit.

\begin{tabular}{|c|c|c|c|c|}
\hline & $\begin{array}{l}\text { Overall } \\
(n=181)\end{array}$ & $\begin{array}{l}\text { Grade } 1 \\
\text { TBE-PP } \\
(n=122)\end{array}$ & $\begin{array}{l}\text { Grade } 2-4 \\
\text { TBE-PP } \\
(n=59)\end{array}$ & $P$ value \\
\hline Male (n, \%) & $104 / 181(57.5)$ & $71(58.2)$ & $33(55.9)$ & 0.873 \\
\hline Mean $(S D)$ age $(n=181)$ & $53.2(17.4)$ & $53.3(17.8)$ & $53.0(16.5)$ & 0.905 \\
\hline Mean (SD) BMI $(n=181)$ & $28.4(7.7)$ & $28.6(7.4)$ & $28.2(8.2)$ & 0.776 \\
\hline Mean (SD) HRM LES length $(n=168)^{1}$ & $3.3(1.1)$ & $3.4(1.1)$ & $3.2(1.1)$ & 0.454 \\
\hline Mean (SD) Eckardt score $(n=181)$ & $7.9(1.8)$ & $8.0(1.9)$ & $7.5(1.7)$ & 0.063 \\
\hline Mean IRP (SD) $(n=181)$ & $29.1(13.2)$ & $28.6(13.5)$ & $30.1(12.4)$ & 0.471 \\
\hline \multicolumn{4}{|l|}{ Motility disorder $(n, \%)(n=181)$} & 0.266 \\
\hline - Type 1 achalasia & $30 / 181(16.6)$ & $16(13.1)$ & $14(23.7)$ & \\
\hline - Type 2 achalasia & $113 / 181(62.4)$ & $77(63.1)$ & $36(61.0)$ & \\
\hline - Type 3 achalasia & $10 / 181(5.5)$ & $8(6.6)$ & $2(3.4)$ & \\
\hline EGJOO & $28 / 181(15.5)$ & $21(17.2)$ & $7(11.9)$ & \\
\hline Previous therapy $(n, \%)(n=181)$ & $95 / 181(52.5)$ & $65(53.3)$ & $30(50.9)$ & 0.874 \\
\hline - Botox & $44 / 181(24.3)$ & $32(26.2)$ & $12(20.3)$ & 0.462 \\
\hline - Pneumatic Dilation & $11 / 181(6.1)$ & $6(4.9)$ & $5(8.5)$ & 0.342 \\
\hline - Heller myotomy & $8 / 181(4.4)$ & $7(5.7)$ & $1(1.7)$ & 0.277 \\
\hline \multicolumn{5}{|l|}{ EGJ-DI $(n, \%)^{2}$} \\
\hline - 20 mL distension $(n=168)$ & $1.6(1.0)$ & $1.5(1.0)$ & $1.7(1.1)$ & 0.224 \\
\hline - 30 mL distension $(n=169)$ & $1.5(1.4)$ & $1.4(1.6)$ & $1.5(1.0)$ & 0.666 \\
\hline - 40 mL distension $(n=168)$ & $1.2(1.1)$ & $1.2(1.2)$ & $1.3(0.8)$ & 0.831 \\
\hline - 50 mL distension $(n=143)$ & $1.1(1.0)$ & $1.1(1.1)$ & $1.0(0.7)$ & 0.663 \\
\hline Sigmoid esophagus $(n, \%)(n=179)^{3}$ & $24 / 179(13.4)$ & $12 / 120(10.0)$ & $12 / 59(20.3)$ & 0.065 \\
\hline Mean (SD) esophageal width $(n=181)$ & $3.4(1.3)$ & $3.1(1.0)$ & $4.0(1.8)$ & $<0.001$ \\
\hline \multicolumn{5}{|l|}{ Myotomy (n, \%) } \\
\hline - Mean length (SD) $(n=181)$ & $9.8(2.5)$ & $9.8(2.7)$ & $9.8(2.2)$ & 0.999 \\
\hline \multicolumn{4}{|l|}{ Intended depth of incision $(\mathrm{n}=181)$} & 0.530 \\
\hline - Circular only & $95 / 181(52.5)$ & $62(50.8)$ & $33(55.9)$ & \\
\hline - Full thickness & $86 / 181(47.5)$ & $60(49.2)$ & $26(44.1)$ & \\
\hline \multicolumn{4}{|l|}{ Orientation $(n=181)$} & 0.279 \\
\hline - Anterior myotomy & $33 / 181(18.2)$ & $19(15.6)$ & $14(23.7)$ & \\
\hline - Posterior myotomy & $130 / 181(71.8)$ & $92(75.4)$ & $38(64.4)$ & \\
\hline - Other & 18/181 (9.9) & $11(9.0)$ & $(11.9)$ & \\
\hline \multicolumn{5}{|c|}{$\begin{array}{l}\text { BMI, body mass index; LES, lower esophageal sphincter; IRP, integrated relaxation pressure; EGJOO, esophagogastric outlet obstruction; TBE-PP, ti } \\
\text { phagram post-POEM; FLIP, function lumen imaging probe. } \\
{ }^{1} \text { Results of LES length by HRM available in } 168 \text { patients. } \\
{ }^{2} \text { Use of FLIP started after POEM in our population and distention to } 50 \mathrm{~mL} \text { after use of FLIP started. Therefore, results not available in all patients. } \\
{ }^{3} \text { Results for sigmoid esophagus available in } 179 \text { patients. }\end{array}$} \\
\hline
\end{tabular}


- Table 2 Clinical response, diagnosis of GERD and results of esophageal manometry and functional luminal impedance planimetry (FLIP) 6 months after POEM stratified by Grade 1 ( $<10 \%$ contrast retention) or Grade 2-4 ( $>10 \%$ contrast retention) post-POEM timed barium esophagram (TBE-PP).

\begin{tabular}{|c|c|c|c|c|}
\hline & $\begin{array}{l}\text { Overall } \\
(n=181)\end{array}$ & $\begin{array}{l}\text { Grade } 1 \\
\text { TBE-PP } \\
(n=122)\end{array}$ & $\begin{array}{l}\text { Grade } 2-4 \\
\text { TBE-PP } \\
(n=59)\end{array}$ & $P$ value \\
\hline \multicolumn{5}{|l|}{ Clinical response } \\
\hline - Eckardt Score $\leq 3(n=181)$ & $166 / 181(91.7)$ & $110 / 122(90.2)$ & $56 / 59(94.9)$ & 0.392 \\
\hline - $I R P<15 \mathrm{~mm} \mathrm{Hg}(n=127)^{1}$ & $110 / 127(86.6)$ & $74 / 85(87.1)$ & $36 / 42(85.7)$ & 1.000 \\
\hline - EGI DI>2.8 at any distention $(n=141)^{2}$ & $135 / 141(95.7)$ & $92 / 94(97.9)$ & $43 / 47(91.5)$ & 0.095 \\
\hline \multicolumn{5}{|l|}{ Esophageal manometry and FLIP } \\
\hline - Mean (SD) ESM IRP $(n=127)^{3}$ & $9.1(6.3)$ & $8.6(5.9)$ & $10.1(6.8)$ & 0.205 \\
\hline - $\mathrm{EGI} \mathrm{DI}>2.8 \mathrm{~mm}^{2} / \mathrm{mm} \mathrm{Hg}$ at $20 \mathrm{~mL}(\mathrm{n}=140)$ & $119 / 140(85.0)$ & $78 / 93(83.9)$ & $41 / 47(87.2)$ & 0.803 \\
\hline - $\mathrm{EGI} \mathrm{DI}>2.8 \mathrm{~mm}^{2} / \mathrm{mm} \mathrm{Hg}$ at $40 \mathrm{~mL}(\mathrm{n}=140)$ & $128 / 140(91.4)$ & $87 / 93(93.6)$ & $41 / 47(87.2)$ & 0.218 \\
\hline 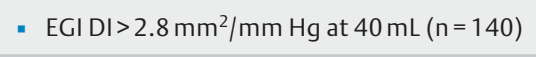 & $128 / 140(91.4)$ & $87 / 93(93.6)$ & $41 / 47(87.2)$ & 0.218 \\
\hline - $\mathrm{EGI} D I>2.8 \mathrm{~mm}^{2} / \mathrm{mm} \mathrm{Hg}$ at $50 \mathrm{~mL}(\mathrm{n}=137)$ & $119 / 137(86.9)$ & $81 / 92(88.0)$ & $38 / 45(84.4)$ & 0.595 \\
\hline - Mean (SD) EGJ-DI at $20 \mathrm{~mL}(n=140)$ & $3.6(2.4)$ & $3.5(1.6)$ & $3.8(3.5)$ & 0.470 \\
\hline - Mean (SD) EGJ-DI at $30 \mathrm{~mL}(n=140)$ & $5.0(2.4)$ & $5.1(2.3)$ & $4.9(2.7)$ & 0.775 \\
\hline - Mean (SD) EGJ-DI at $40 \mathrm{~mL}(\mathrm{n}=140)$ & $5.6(2.5)$ & $5.6(2.5)$ & $5.5(2.6)$ & 0.846 \\
\hline - Mean (SD) EGJ-DI at $50 \mathrm{~mL}(\mathrm{n}=137)$ & $4.9(2.2)$ & $4.9(2.2)$ & $5.0(2.2)$ & 0.901 \\
\hline GERD by Lyon Criteria $(n=127)^{4}$ & $87 / 127(68.6)$ & $61 / 85(71.8)$ & $26 / 42(61.9)$ & 0.311 \\
\hline \multicolumn{4}{|l|}{ Esophagitis grade $(n=146)^{5}$} & 0.191 \\
\hline - None & $44 / 146(30.1)$ & $23 / 96(24.0)$ & $21 / 50(42.0)$ & \\
\hline - LA Grade A & $33 / 146(22.6)$ & $22 / 96(22.9)$ & $11 / 50(22.6)$ & \\
\hline - LA Grade B & $47 / 146(32.2)$ & $34 / 96(35.4)$ & $13 / 50(26.0)$ & \\
\hline - LA Grade C & $16 / 146(11.0)$ & $13 / 96(13.5)$ & $3 / 50(6.0)$ & \\
\hline - LA Grade D & $6 / 146(4.1)$ & $4 / 96(4.2)$ & $2 / 50(4.0)$ & \\
\hline Heartburn $(n=174)^{6}$ & $55 / 174(31.6)$ & $36 / 119(30.3)$ & $19 / 55(34.6)$ & 0.601 \\
\hline \multicolumn{4}{|l|}{ Taking PPIs $(n=176)^{7}$} & 0.086 \\
\hline - \% No (n) & $121 / 176(68.8)$ & $87 / 119(71.0)$ & $34 / 57(59.6)$ & \\
\hline - \% Weekly (n) & 28/176(15.9) & $14 / 119(11.8)$ & $14 / 57(24.6)$ & \\
\hline . \% Daily (n) & $27 / 156(15.3)$ & $18 / 119(15.1)$ & $9 / 57(15.8)$ & \\
\hline $\begin{array}{l}\text { IRP, integrated relaxation pressure; TBE-PP, timed ba } \\
{ }^{1} \text { HRM } 6 \text { months after POEM was available in } 127 \text { pa } \\
{ }^{2} \text { FLIP } 6 \text { months after POEM was available in } 140 \text { patie } \\
\text { results at } 50 \mathrm{~mL} \text { were not available in all patients. } \\
{ }^{3} \mathrm{HRM} 6 \text { months after POEM was available in } 127 \text { pa } \\
{ }^{4} \text { GERD diagnosed } 6 \text { months after POEM was classifie } \\
121 \text { patients. } \\
{ }^{5} \text { EGD } 6 \text { months after POEM to evaluate for esophag } \\
{ }^{6} \text { Patient reported symptoms of heartburn } 6 \text { months } \\
{ }^{7} \text { Patient reported use of PPIs } 6 \text { months after POEM }\end{array}$ & $\begin{array}{l}\text { sophagram post-PO } \\
\text { se of FLIP started aft } \\
\text { he Lyon Criteria base } \\
\text { done in } 146 \text { patien } \\
\text { POEM were available } \\
\text { vailable in } 176 \text { patie }\end{array}$ & $\begin{array}{l}\text { esophagogastric jun } \\
\text { ur population and di } \\
\text { ilability of EGD, wir } \\
\text { nts. }\end{array}$ & $\begin{array}{l}\text { nsibility index. } \\
50 \mathrm{~mL} \text { after use } \\
\text { sting or both. pH }\end{array}$ & $\begin{array}{l}\text { ed. Therefore } \\
\text { is available in }\end{array}$ \\
\hline
\end{tabular}

\section{Discussion}

In this, single center study of 181 patients with achalasia or EGJOO treated with POEM, we found that rapid esophageal emptying ( $<10 \%$ contrast retention) 2 minutes after a timed barium esophagram (TBE-PP) within 24 hours of the procedure does not predict short-term (6 month) clinical response by Eckardt score, IRP or EGJ-DI. Two years after POEM, patients with rapid emptying were more likely to achieve a normalized IRP compar- 
- Table 3 Clinical response, diagnosis of GERD and results of esophageal manometry and functional luminal impedance planimetry (FLIP) 24 months after POEM stratified by Grade 1 ( $<10 \%$ contrast retention) or Grade $2-4$ ( $<10 \%$ contrast retention) post-POEM timed barium esophagram (TBE-PP).

\begin{tabular}{|c|c|c|c|c|}
\hline & $\begin{array}{l}\text { Overall } \\
(n=73)\end{array}$ & $\begin{array}{l}\text { Grade } 1 \\
\text { TBE-PP } \\
(n=50)\end{array}$ & $\begin{array}{l}\text { Grade } 2-4 \text { TBE-PP } \\
(n=23)\end{array}$ & $P$ value \\
\hline \multicolumn{5}{|l|}{ Clinical Response } \\
\hline - Eckardt Score $\leq 3(n=73)$ & $67 / 73(91.2)$ & $47 / 50(94.0)$ & $20 / 23(87.0)$ & 0.37 \\
\hline - $I R P<15 \mathrm{~mm} \mathrm{Hg}(n=33)^{1}$ & $28 / 33(84.9)$ & $22 / 23(95.7)$ & $6 / 10(60.0)$ & 0.02 \\
\hline - EGI DI<2.8 at any distention $(n=39)^{2}$ & $36 / 39(92.3)$ & $24 / 26(92.3)$ & $12 / 13(92.3)$ & 1.0 \\
\hline \multicolumn{5}{|l|}{ Esophageal Manometry and FLIP } \\
\hline - Mean (SD) IRP $(n=33)^{3}$ & $10.3(5.7)$ & $8.2(3.5)$ & $15.2(6.8)$ & $<0.001$ \\
\hline 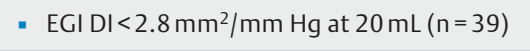 & $24 / 39(61.5)$ & $17 / 26(65.4)$ & $7 / 13(53.9)$ & 0.51 \\
\hline 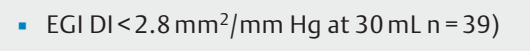 & $33 / 39(84.6)$ & $21 / 26(66.7)$ & $12 / 13(92.3)$ & 0.64 \\
\hline - $\mathrm{EGI} \mathrm{DI}<2.8 \mathrm{~mm}^{2} / \mathrm{mm} \mathrm{Hg}$ at $40 \mathrm{~mL}(\mathrm{n}=39)$ & $34 / 39(87.2)$ & $22 / 26(84.6)$ & $12 / 13(92.3)$ & 0.65 \\
\hline - $\mathrm{EGI} \mathrm{DI}<2.8 \mathrm{~mm}^{2} / \mathrm{mm} \mathrm{Hg}$ at $50 \mathrm{~mL}(\mathrm{n}=39)$ & $31 / 39(79.5)$ & $21 / 26(80.8)$ & $10 / 13(76.9)$ & 1.0 \\
\hline - Mean (SD) EGJ-DI at $20 \mathrm{~mL}(\mathrm{n}=39)$ & $3.5(1.5)$ & $3.6(1.5)$ & $3.3(1.6)$ & 0.68 \\
\hline - Mean (SD) EGJ-DI at $30 \mathrm{~mL}(\mathrm{n}=39)$ & $4.7(1.7)$ & $4.8(1.8)$ & $4.7(1.7)$ & 0.89 \\
\hline - Mean (SD) EGJ-DI at $40 \mathrm{~mL}(\mathrm{n}=39)$ & $5.1(1.9)$ & $5.1(1.9)$ & $5.2(1.9)$ & 0.88 \\
\hline - Mean (SD) EGJ-DI at $50 \mathrm{~mL}(\mathrm{n}=39)$ & $4.7(1.7)$ & $4.7(1.6)$ & $4.7(1.8)$ & 0.92 \\
\hline GERD by Lyon Criteria $(n=35)^{4}$ & $26 / 35(74.3)$ & $18 / 24(75.0)$ & $8 / 11(72.7)$ & 1.0 \\
\hline \multicolumn{4}{|l|}{ Esophagitis Grade $(n=39)^{5}$} & 0.37 \\
\hline - None & $9 / 39(23.1)$ & $6 / 26(23.1)$ & $3 / 13(23.1)$ & 1.0 \\
\hline - $A$ & $11 / 39(28.2)$ & $5 / 26(19.2)$ & $6 / 13(46.2)$ & 0.13 \\
\hline - $B$ & $14 / 39(35.9)$ & $10 / 26(38.5)$ & $4 / 13(30.8)$ & 0.73 \\
\hline. $\mathrm{C}$ & $3 / 39(7.7)$ & $3 / 26(11.5)$ & $0 / 13(0.0)$ & 0.54 \\
\hline . $\mathrm{D}$ & $2 / 39(5.1)$ & $2 / 26(7.7)$ & $0 / 13(0.0)$ & 0.54 \\
\hline Heartburn $(n=47)^{6}$ & $20 / 47(42.6)$ & $17 / 32(53.1)$ & $3 / 15(20.0)$ & 0.056 \\
\hline \multicolumn{4}{|l|}{ Taking PPIs $(n=47)^{7}$} & 0.29 \\
\hline - \% No (n) & $35 / 47(74.5)$ & $22 / 32(68.8)$ & $13 / 15(86.7)$ & \\
\hline - \% Weekly (n) & $12 / 47(25.5)$ & $10 / 32(31.2)$ & $2 / 15(13.3)$ & \\
\hline - \% Daily (n) & $0 / 47(0.0)$ & $0 / 32(0.0)$ & $0 / 15(0.0)$ & \\
\hline $\begin{array}{l}\text { IRP, integrated relaxation pressure; TBE-PP, timed b } \\
{ }^{1} \text { HRM } 24 \text { months after POEM was available in } 33 \text { pa } \\
2 \text { FLIP } 24 \text { months after POEM was available in } 39 \text { pa } \\
{ }^{3} \text { HRM } 24 \text { months after POEM was available in } 33 \text { pa } \\
{ }^{4} \text { GERD diagnosed } 24 \text { months after POEM was classi } \\
33 \text { patients. } \\
{ }^{5} \text { EGD } 24 \text { months after POEM to evaluate for esoph } \\
{ }^{6} \text { Patient reported symptoms of heartburn } 24 \text { mont } \\
{ }^{7} \text { Patient reported use of PPIs } 24 \text { months after POE }\end{array}$ & $\begin{array}{l}\text { sophagram post-1 } \\
\text { he Lyon Criteria ba } \\
\text { as done in } 39 \text { patic } \\
\text { POEM were availc }\end{array}$ & $\begin{array}{l}\text { ailability of EGD, v } \\
\text { ents. }\end{array}$ & sting or both. pH testing & s performed in \\
\hline
\end{tabular}

ed to those with mild-severe delayed emptying ( $\geq 10 \%$ contrast retention). After adjusting for baseline IRP and other clinical characteristics, patients with rapid esophageal transit after POEM had lower IRP scores at 24 months than patients with slower transit (>10\% contrast retention). However, clinical response at 24 months by Eckardt score and EGJ-DI and the inci- dence of GERD, heartburn, esophagitis and PPI use were similar between the two groups.

Timed barium esophagram (TBE) is used to estimate esophageal emptying either before or after intervention for esophageal motility disorders. It is typically administered with a large volume of barium (i.e., $200-250 \mathrm{~mL}$ ) and measurements of contrast column height or quantity remaining are taken at two 
- Table4 Previous studies reporting the frequency of contrast leaks identified on CT scan or fluoroscopic esophagram by after per-oral endoscopic myotomy.

\begin{tabular}{|c|c|c|c|c|c|c|c|}
\hline $\begin{array}{l}\text { Author } \\
\text { (yr) }\end{array}$ & $\mathbf{N}$ & $\begin{array}{l}\text { Study } \\
\text { settings }\end{array}$ & $\begin{array}{l}\text { Method of } \\
\text { esopha- } \\
\text { gram }\end{array}$ & $\begin{array}{l}\text { Extramur- } \\
\text { al leaks } \\
\mathrm{n},(\%)\end{array}$ & $\begin{array}{l}\text { Contained } \\
\text { leaks } \\
\mathrm{n},(\%)\end{array}$ & $\begin{array}{l}\text { Frequency esophagram } \\
\text { findings altered man- } \\
\text { agement }\end{array}$ & Notes \\
\hline $\begin{array}{l}\text { Pannu } \\
\text { (2016) }\end{array}$ & 84 & $\begin{array}{l}\text { Single-cen- } \\
\text { ter pro- } \\
\text { spective }\end{array}$ & CTscan & $1(1.2 \%)$ & $0(\%)$ & $\begin{array}{l}1(1.2 \%) \text {. } \\
\text { Repeat EGD in this pa- } \\
\text { tient showed ulcer, un- } \\
\text { successfully treated with } \\
\text { OTSC. } \\
\text { Required surgical myot- } \\
\text { omy }\end{array}$ & $\begin{array}{l}\text { Extensive coagulation of } \\
\text { gastric cardia vessels } \\
\text { done during POEM in this } \\
\text { patient }\end{array}$ \\
\hline $\begin{array}{l}\text { Levy } \\
\text { (2016) }\end{array}$ & 25 & $\begin{array}{l}\text { Single-cen- } \\
\text { ter, retro- } \\
\text { spective }\end{array}$ & $\begin{array}{l}\text { Fluoro- } \\
\text { scopy }\end{array}$ & $0(0 \%)$ & $7(28 \%)$ & NA & \\
\hline $\begin{array}{l}\text { El } \\
\text { Khoury } \\
(2016)\end{array}$ & 78 & $\begin{array}{l}\text { Single-cen- } \\
\text { ter, retro- } \\
\text { spective }\end{array}$ & $\begin{array}{l}\text { Fluoro- } \\
\text { scopy }\end{array}$ & $0(0 \%)$ & $1(2 \%)$ & $2(4 \%)$ & $\begin{array}{l}\text { Clinical findings would } \\
\text { have prompted these two } \\
\text { esophagrams }\end{array}$ \\
\hline $\begin{array}{l}\text { Nast } \\
(2018)\end{array}$ & 114 & $\begin{array}{l}\text { Single-cen- } \\
\text { ter, retro- } \\
\text { spective }\end{array}$ & $\begin{array}{l}\text { Fluoro- } \\
\text { scopy }\end{array}$ & $0(0 \%)$ & $2(1.7 \%)$ & $2(1.7 \%)$ & $\begin{array}{l}1 / 2 \text { was false positive } \\
\text { esophagram }\end{array}$ \\
\hline $\begin{array}{l}\text { Reddy } \\
(2021)\end{array}$ & 170 & $\begin{array}{l}\text { Multicen- } \\
\text { ter, retro- } \\
\text { spective }\end{array}$ & $\begin{array}{l}\text { Fluorosco- } \\
\text { Py }(n=139) \\
\text { and CT } \\
(n=31)\end{array}$ & $0(\%)$ & $5(2.9 \%)$ & $\begin{array}{l}2(1.2 \%) \text {. } \\
\text { Repeat EGD and clipping } \\
\text { in these two leaks. These } \\
\text { were considered true po- } \\
\text { sitive leaks. }\end{array}$ & $\begin{array}{l}\text { 2/4 leaks occurred with } \\
\text { inadvertent mucosotomy } \\
\text { (1) or thermal injury ( } 1) \text {. } \\
\text { 2/4 found after patient } \\
\text { decompensation and } \\
\text { were considered false- } \\
\text { negative PPEs }\end{array}$ \\
\hline $\begin{array}{l}\text { Current } \\
\text { study }\end{array}$ & 181 & $\begin{array}{l}\text { Single-cen- } \\
\text { ter, retro- } \\
\text { spective }\end{array}$ & $\begin{array}{l}\text { Fluoro- } \\
\text { scopy }\end{array}$ & $0(0 \%)$ & $7(3.8 \%)$ & $\begin{array}{l}1 / 181(0.6 \%) \\
\text { Fully covered stent inser- } \\
\text { ted } \\
\text { in } 1 \text { patient who also had } \\
\text { intraprocedural pneu- } \\
\text { mothorax } \\
\text { requiring chest tube. }\end{array}$ & \\
\hline Total & 652 & & $\begin{array}{l}\text { Fluoro- } \\
\text { scopy } \\
\text { ( } n=537) \text {, } \\
\text { CT scan } \\
(n=115)\end{array}$ & $1(0.15 \%)$ & $22(3.4 \%)$ & $8 / 652(1.2 \%)$ & \\
\hline
\end{tabular}

CT, computed tomography; EGD, esophagogastroduodenoscopy; POEM, per-oral endoscopic myotomy; OTSC, over-the-scope clip.

or three intervals up to 5 minutes [10,24]. For this study, we used a timed esophagram protocol with gastrograffin followed by barium (total about $200 \mathrm{mLs}$ contrast) with measurements up to only 2 minutes as we anticipated most patients would have little contrast remaining after POEM and evaluation for esophageal leaks could be adequately completed during this time period. Furthermore, we used a novel grading scale to quantitate the contrast retention to predict clinical response after POEM to patient-reported outcomes (Eckardt scale) or objective measurements (IRP, EGJ-DI or development of GERD).

Previous studies have reported that TBE following pneumatic dilation may identify patients who require repeat intervention [11] and is more effective than patient-reported outcomes to predict treatment response [12]. Furthermore, wider esophageal diameter, higher barium column height or poor emptying from TBE following Heller myotomy for achalasia reportedly may predict risk of procedure failure or lack of symptom relief [24-28]. However, previous studies suggest that delay in contrast passage after POEM does not predict clinical outcomes $[4,13,14]$ and often reports findings that are clinically irrelevant in stable patients and may lead to unnecessary post-procedure interventions [6-9]. We found that 2 years after POEM, after adjusting for baseline IRP and other clinical characteristics, rapid $(<10 \%$ retention) predicted a lower IRP compared to those with mild-severe contrast delay but did not predict a normalized Eckardt score or other variables assessed. It is important to note that the value of TBE after interventions for achalasia are difficult to correlate due to a paucity of prospective studies with standardized esophagram protocols. Furthermore, studies after pneumatic dilation and POEM are usually per- 
formed in the immediate post-procedure period to assess for complications whereas studies after Heller myotomy are performed usually months to years after myotomy to test esophageal emptying function and evaluate for need for reintervention. These findings after various interventions also underscore the disparity that often occurs between patient-reported symptoms in achalasia and results of esophageal physiology and radiographic studies [12, 29-31].

Our study also found that contained submucosal leaks on post-POEM esophagrams in clinically stable patients may not require intervention with repeat endoscopy. In six of seven patients with this finding, a liquid diet was started within 24 hours of POEM with no adverse effects. In the only unstable patient who had an intraprocedural pneumothorax during POEM, a fully-covered esophageal stent was placed after esophagram showed a contained leak. In the remaining 174 patients, there were no findings on esophagram that prompted change in clinical care in the immediate post-procedure period. Thus, results of one of 181 (0.6\%) TBE-PP exams in the current study caused a change in clinical management and only in a clinically unstable patient. When our data is combined with four other studies [4-6, 8] with 652 patients (537 fluoroscopic esophagrams or 115 CT scans), contained (intramural) leaks are noted in $3.4 \%$ of studies after POEM and results of these changed management in only $1.2 \%$ of patients ( $\triangleright$ Table 4 ). As other studies have suggested $[5,6,9]$ these findings collectively suggest that CT or esophagram may not be warranted in the immediate postoperative period in patients who clinically stable and did not incur iatrogenic mucosal injuries or insecure mucosotomy closures [5,32]. Similarly, some authors have questioned the value of post procedure manometry to evaluate response to myotomy [33].

The current study represents the largest study to date evaluating the correlation between the rate of post-procedure esophagram contrast transport and clinical outcomes after POEM. Furthermore, a strict esophagram protocol was used to compare transit times to important patient-reported outcomes (Eckardt scores), lower esophageal sphincter measurements (IRP, EGJ-DI) and incidence of heartburn, PPI use and GERD. However, our study does have several weaknesses. First, follow-up short- and long-term objective testing was not available in all patients. Second, TBE protocol limited testing to a maximum of 2 minutes and the contrast grading scale used has not been validated by other authors. Third, the low frequency of contained leaks limits generalizations about the safety of conservative management of these patients. Finally, no pre-POEM TBE was available to compare findings from post-POEM esophagram.

\section{Conclusions}

In conclusion, rapid contrast transit by timed fluoroscopic esophagram within 24 hours of POEM for achalasia or EGJOO predicts long-term normalization of IRP after POEM. Rapid emptying does not predict other short-term or long-term clinical responses, patient-reported outcomes, PPI use, or risk of postprocedure GERD. In clinically stable patients after POEM con- tained leaks may be managed conservatively without intervention. These findings suggest that esophageal imaging after POEM may not be necessary in clinically stable patients or those in whom the procedure was completed without transmural mucosal injuries or possible incomplete submucosal tunnel closure. We recommend this instead should be reserved for signs of clinical deterioration or refractory symptoms in the perioperative period.

\section{Competing interests}

Dr. DeWitt is a consultant for Boston Scientific, Inc. Dr. Al-Haddad is a consultant for Boston Scientific Inc.

\section{Clinical trial}

clinicaltrials.gov

NCT02770859

TRIAL REGISTRATION: Single-Center, Retrospective Trial

NCT02770859 at clinicaltrials.gov

\section{References}

[1] Vaezi MF, Pandolfino JE, Yadlapati RH et al. ACG Clinical Guidelines: Diagnosis and Management of Achalasia. Am J Gastroenterol 2020; 115: 1393-1411

[2] Werner YB, Hakanson B, Martinek J et al. Endoscopic or surgical myotomy in patients with idiopathic achalasia. N Engl J Med 2019; 381: 2219-2229

[3] Ponds FA, Fockens P, Lei A et al. Effect of peroral endoscopic myotomy vs pneumatic dilation on symptom severity and treatment outcomes among treatment-naive patients with achalasia: a randomized clinical trial. JAMA 2019; 322: 134-144

[4] Levy JL, Levine MS, Rubesin SE et al. Findings of esophagography for 25 patients after peroral endoscopic myotomy for achalasia. AJR Am J Roentgenol 2016; 207: 1185-1193

[5] El Khoury R, Teitelbaum EN, Sternbach JM et al. Evaluation of the need for routine esophagram after peroral endoscopic myotomy (POEM). Surg Endosc 2016; 30: 2969-2974

[6] Nast JF, Berliner C, Rösch T et al. Endoscopy versus radiology in postprocedural monitoring after peroral endoscopic myotomy (POEM). Surg Endosc 2018; 32: 3956-3963

[7] Reddy CA, Tavakkoli A, Abdul-Hussein M et al. Clinical impact of routine esophagram after peroral endoscopic myotomy. Gastrointest Endosc 2021; 93: 102-106

[8] Pannu D, Yang D, Abbitt PL et al. Prospective evaluation of CT esophagram findings after peroral endoscopic myotomy. Gastrointest Endosc 2016; 84: 408-415

[9] Cai MY, Zhou PH, Yao LQ et al. Thoracic CT after peroral endoscopic myotomy for the treatment of achalasia. Gastrointest Endosc 2014; 80: 1046-1055

[10] de Oliveira JM, Birgisson S, Doinoff $C$ et al. Timed barium swallow: a simple technique for evaluating esophageal emptying in patients with achalasia. AJR Am J Roentgenol 1997; 169: 473-479

[11] Vaezi MF, Baker ME, Richter JE. Assessment of esophageal emptying post-pneumatic dilation: use of the timed barium esophagram. Am J Gastroenterol 1999; 94: 1802-1807 
[12] Vaezi MF, Baker ME, Achkar E et al. Timed barium oesophagram: better predictor of long-term success after pneumatic dilation in achalasia than symptom assessment. Gut 2002; 50: 765-770

[13] Sternbach JM, El Khoury R, Teitelbaum EN et al. Early esophagram in per-oral endoscopic myotomy (POEM) for achalasia does not predict long-term outcomes. Surgery 2015; 158: 1128-1135; discussion 1135-1136

[14] Sanaka MR, Chadalavada P, Covut F et al. Clinical success and correlation of eckardt scores with barium esophagram after peroral endoscopic myotomy in achalasia. J Gastrointest Surg 2021; 25: 278-281

[15] Eckardt VF, Aignherr C, Bernhard G. Predictors of outcome in patients with achalasia treated by pneumatic dilation. Gastroenterology 1992 103: $1732-1738$

[16] Kahrilas PJ, Bredenoord AJ, Fox M et al. International High Resolution Manometry Working Group. The Chicago Classification of esophageal motility disorders, v3.0. Neurogastroenterol Motil 2015; 27: 160-174

[17] Pandolfino JE, de Ruigh A, Nicodème F et al. Distensibility of the esophagogastric junction assessed with the functional lumen imaging probe (FLIPTM) in achalasia patients. Neurogastroenterol Motil 2013; 25: 496-501

[18] Roll GR, Rabl C, Ciovica R et al. A controversy that has been tough to swallow: is the treatment of achalasia now digested? J Gastrointest Surg 2010; 14: S33-S45

[19] Lundell LR, Dent J, Bennett JR et al. Endoscopic assessment of oesophagitis: clinical and functional correlates and further validation of the Los Angeles classification. Gut 1999; 45: 172-180

[20] Lawenko RM, Lee YY. Evaluation of gastroesophageal reflux disease using the bravo capsule pH system. J Neurogastroenterol Motil 2016; 22: $25-30$

[21] Gyawali CP, Kahrilas PJ, Savarino E et al. Modern diagnosis of GERD: the Lyon Consensus. Gut 2018; 67: 1351-1362

[22] Eckardt VF, Aignherr C, Bernhard G. Predictors of outcome in patients with achalasia treated by pneumatic dilation. Gastroenterology 1992; 103: $1732-1738$
[23] Carlson DA, Kou W, Lin Z et al. Normal values of esophageal distensibility and distension-induced contractility measured by functional luminal imaging probe panometry. Clin Gastroenterol Hepatol 2019; 17: 674-681

[24] Kostic SV, Rice TW, Baker ME et al. Timed barium esophagogram: A simple physiologic assessment for achalasia. J Thorac Cardiovasc Surg 2000; 120: 935-943

[25] Tsoukali E, Gouvas N, Tsiaoussis J et al. Specific esophagogram to assess functional outcomes after Heller's myotomy and Dor's fundoplication for esophageal achalasia. Dis Esophagus 2011; 24: 451-457

[26] Andersson M, Lundell L, Kostic S et al. Evaluation of the response to treatment in patients with idiopathic achalasia by the timed barium esophagogram: results from a randomized clinical trial. Dis Esophagus 2009; 22: 264-273

[27] Kachala SS, Rice TW, Baker ME et al. Value of routine timed barium esophagram follow-up in achalasia after myotomy. J Thorac Cardiovasc Surg 2018; 156: 871-877

[28] Oezcelik A, Hagen JA, Halls JM et al. An improved method of assessing esophageal emptying using the timed barium study following surgical myotomy for achalasia. J Gastrointest Surg 2009; 13: 14-18

[29] Zanoni A, Rice TW, Lopez R et al. Timed barium esophagram in achalasia types. Dis Esophagus 2015; 28: 336-344

[30] Vela MF, Richter JE, Khandwala F et al. The long-term efficacy of pneumatic dilatation and Heller myotomy for the treatment of achalasia. Clin Gastroenterol Hepatol 2006; 4: 580-587

[31] Blam ME, Delfyett W, Levine MS et al. Achalasia: a disease of varied and subtle symptoms that do not correlate with radiographic findings. Am J Gastroenterol 2002; 97: 1916-1923

[32] Shah R, Cai Q. Clinical utility of routine post-peroral endoscopic myotomy imaging: Does clinical decision making outweigh the protocol. Gastrointest Endosc 2021; 93: 107-109

[33] Foisy H, Pioche M, Chabrun E et al. Role of rapid drink challenge during esophageal high-resolution manometry in predicting outcome of peroral endoscopic myotomy in patients with achalasia. J Neurogastroenterol Motil 2020; 26: 204-214 